\title{
Contemporary review of risk-stratified management in acute uncomplicated and complicated diverticulitis
}

Prof. Marja A. Boermeester, MD¹, Mr. David J. Humes PhD 2*, Prof. George C. Velmahos $M D^{3}$, Prof. Kjetil Søreide, $M D^{4,5}$

1. Department of Surgery, Academic Medical Center, Amsterdam, The Netherlands

2. Division of Epidemiology and Public Health, School of Community Health Sciences, University of Nottingham, Clinical Sciences Building 2, City Hospital, Nottingham, UK

3. Division of Trauma Emergency Surgery and Surgical Critical Care, Massachusetts General Hospital and Harvard Medical School, Boston, Massachusetts, USA

4. Department of Gastrointestinal Surgery, Stavanger University Hospital, P. O. Box 8100, N-4068 Stavanger, Norway;

5. Department of Clinical Medicine, University of Bergen, Bergen, Norway

* correspondence/reprints:

Mr David Humes. Division of Epidemiology and Public Health, School of Community Health Sciences, University of Nottingham, Clinical Sciences Building 2, City Hospital, Nottingham, UK. David.humes@nottingham.ac.uk. Tel:00441158231153

Funding: DJH is funded by a National Institute for Health Research PostDoctoral Fellowship.

Running head: Management of acute diverticulitis 


\section{Structured Abstract}

BACKGROUND: Acute colonic diverticulitis is a common clinical condition. Severity of the disease is based on clinical, laboratory and radiological investigations and dictates the need for medical or surgical intervention. Recent clinical trials have improved the understanding of the natural history of the disease resulting in new approaches to and better evidence for the management of acute diverticulitis. METHODS: We searched the Cochrane Library (years 2004-2015), MEDLINE (years 2004-2015), and EMBASE (years 2004-2015) databases. We used the search terms "diverticulitis, colonic" or "acute diverticulitis" or "divertic" in combination with the terms "management”, “antibiotics”, “non-operative” or "surgery”. Registers for clinical trials (such as the WHO registry and the clinicaltrial.gov) were searched for ongoing, recruiting, or closed trials not yet published.

RESULTS: Antibiotic treatment can be avoided in simple, non-complicated diverticulitis and outpatient management is safe. The management of complicated disease, ranging from a localized abscess to perforation with diffuse peritonitis, has changed towards either percutaneous or minimally invasive approaches in selected cases. The role of laparoscopic lavage without resection in perforated non-fecal diverticulitis is still debated however recent evidence from two RCT's has found a higher re-intervention in this group of patients.

CONCLUSIONS: A shift in management has occurred towards conservative management in acute uncomplicated disease. Those with uncomplicated acute diverticulitis may be treated without antibiotics. For complicated diverticulitis with purulent peritonitis, the use of peritoneal lavage appears to be non-superior to resection. 


\section{Introduction}

Acute diverticulitis is among the top ten diagnoses of patients presenting to the general physician or at the emergency department with acute abdominal pain. [1] The role of the clinician is to establish the severity of the disease, based on the clinical findings and results of appropriate investigations. This will then determine the subsequent need for medical or surgical intervention. As evident from a number of guidelines issued in the past, there has been considerable variation in recommendations and approaches to patients with acute diverticulitis[2-8]. Much of the variation has been based on a weak or complete lack of evidence for which to make recommendations. Also, considerable variation in strategies and management choices still exist between and within regions $[9,10]$. As our understanding of this disease has evolved, so have the available strategies for managing it. As a consequence a less invasive approach to the medical and surgical treatment of acute diverticulitis has emerged.

In this contemporary review we report on the recent understanding of acute diverticulitis as a spectrum between simple, self-resolving disease to the need for medical, radiological and surgical intervention. We aimed to review the best evidence for a stratified management of patients with either acute uncomplicated or complicated diverticulitis. 


\section{Methods}

We aimed to identify studies which reported on the diagnosis of acute diverticulitis along with its subsequent medical and surgical management. The following databases were searched including the Cochrane Library (years 2004-2015), MEDLINE (years 2004-2015), and EMBASE (years 2004-2015). We used the search terms "diverticulitis, colonic" or "acute diverticulitis" or "divertic*" in combination with the terms "management", "antibiotics”, "non-operative” or "surgery". We included systematic reviews and meta-analyses pertinent to the topics, along with reported RCT's and cohort studies. Registers for clinical trials (such as the WHO registry and the clinicaltrial.gov) were searched for ongoing, recruiting, or closed trials not yet published. We largely selected publications from the search period in the English language, but did not exclude commonly referenced and highly regarded older publications. We also searched the reference lists of articles identified by this search strategy and selected those we judged relevant by the above criteria.

A formal grading of all evidence, such as by the Oxford Evidence Based Medicine (CEBM) or Grading of Recommendations Assessment, Development and Evaluation (GRADE), was not systematically done, unless already performed and reported in identified studies. However, the type of study or collective data were specifically cited where applicable and, where evidence is weak or even lacking, this has been commented on in each specific section. 


\section{Results}

In patients with acute abdominal pain presenting to the emergency department, reliance on clinical diagnosis of diverticulitis can result in too many missed diagnoses of diverticulitis (up to $36 \%$ ) or incorrect suspicion of diverticulitis.[11-13] A simplified clinical decision rule has been proposed with an excellent positive predictive value (81-100\%) for diagnosis of acute diverticulitis in patients who present with the complete triad of 'absence of vomiting', 'tenderness in the left lower quadrant', and 'CRP of more than $50 \mathrm{mg} / \mathrm{L}$ '. However, the triad alone identifies only up to $25 \%$ of patients with diverticulitis. [13] Imaging is thus important to increase diagnostic accuracy and allow risk stratification early in the clinical course.

\section{Diagnostic imaging}

In studies with selected patients computed tomography (CT) demonstrates high accuracy for the diagnosis of acute diverticulitis with a sensitivity of $94 \%$ (87-97\%) and specificity of $99 \%(90-100 \%) .[14,15]$ CT is better than ultrasound (US) in detecting an alternative diagnosis in patients with clinical suspicion of diverticulitis and allows better detection of complicated disease. In a large prospective cohort of unselected patients, presenting with acute abdominal pain, sensitivity for the diagnosis of acute diverticulitis was somewhat lower $(81 \%(74-88 \%))$ than in selected patients but specificity remained high (99\% (98-99\%)).[14] US had a moderate sensitivity $(61 \%(52-70 \%))$ but a good specificity $(99 \%(99-100 \%))$ for the diagnosis of acute diverticulitis in an unselected population. [14] 
As treatment strategies have become less aggressive and more tailored to the stage of diverticulitis, accurate staging of the disease has become increasingly important (Table 1). Hinchey's traditional classification (Figure 1) for perforated diverticulitis from 1978 was based on clinical and surgical findings. [16, 17] The modern Hinchey classification is a fully CT-based modification of the original Hinchey classification.[18] Ambrosetti defined a further classification based on CT imaging.[19] Both classifications do not specify the various stages of complicated diverticulitis. A new CT-based classification focuses on complicated diverticulitis only which is an important extension of existing classifications (Table 2). [20] Classification may help to compare patients across cohorts and to identify patients at risk of further complications, such as those with small abscesses. It may also allow identification of patients for successful conservative treatment of complicated diverticulitis.

\section{Treatment strategies}

The treatment of acute diverticulitis is stratified and should be considered either as treatment of a mild and non-complex inflammatory disease (which is often selflimiting), or treatment of a severe and complex disease with systemic affection. Traditionally patients were put nil by mouth, prescribed intravenous antibiotics and admitted to hospital as part of the treatment regimen.

\section{Uncomplicated acute diverticulitis}

\section{Outpatient management}

Outpatient management of patients with simple uncomplicated acute diverticulitis 
is feasible in those with tolerance to oral intake, no severe comorbidity, and with appropriate social support. [5] There is no published evidence that dietary alterations (e.g. high-fiber diets) or laxatives have any effect on disease outcome.[5]

\section{Indications and role of antibiotics}

Simple acute diverticulitis is in the majority of cases a self-limiting process. Antibiotics are still routinely prescribed in many cases of uncomplicated disease and continue to be recommended in some guidelines.[21] A Cochrane systematic review from 2012 concluded that the role of antibiotics in uncomplicated acute diverticulitis is not adequately investigated.[22] However, recent studies on the best treatment for $\mathrm{CT}$ proven mild, uncomplicated diverticulitis demonstrate that these patients can be managed expectantly without antibiotics, either as inpatients or outpatients according to the severity of the complaints (Table 2).[23] One randomized controlled trial (AVOD trial) demonstrated no benefit of routine use of antibiotics over no antibiotics in terms of complications, need for emergency surgery, hospital stay, or recurrence at 12 months in 623 patients with mild diverticulitis.[24] Unfortunately, $40 \%$ of the included patients in this trial had a recurrent episode of diverticulitis rather than a primary episode. A long accrual period and no standardized antibiotic treatment may also have resulted in a performance bias. A second RCT, with a multicenter, randomized, controlled, pragmatic, non-inferiority design (DIABOLO) found no difference in median time-torecovery, readmission rates, complications, recurrent diverticulitis, or need for sigmoid resection in 528 patients with a CT-proven first episode of acute, leftsided, uncomplicated diverticulitis, between antibiotic treatment or simply 
observation.[25]

\section{Complicated acute diverticulitis}

The management of complicated diverticulitis continues to be debated.

Complicated diverticulitis includes acute diverticulitis with abscesses (Hinchey II), purulent peritonitis (Hinchey III), and fecal peritonitis (Hinchey IV). Clearly, patients who are septic after perforated diverticulitis or have diffuse peritonitis with evidence of free air require an immediate operation. On the other hand, those who are non-septic and have contained perforations may be managed operatively or non-operatively, depending on subtle clinical details and the evolution of the course of the disease.

In the absence of compelling symptoms and signs, Hinchey grade I or II diverticulitis is usually managed without surgery. Hinchey II disease is frequently treated with antibiotics and percutaneous drainage (for abscess size $>5 \mathrm{~cm}$ ). Hinchey III and IV disease typically requires an operation. The controversy concerns the need for resection with a diverting stoma (so-called Hartmann's procedure) versus resection with a primary anastomosis. Added to the debate, is the approach of laparoscopic lavage (with no resection) for perforation and generalized peritonitis (Hinchey grade III) without fecal contamination.

\section{Evolving treatment strategies}

The treatment of diverticulitis has evolved towards a more conservative and minimally invasive approach [FIGURE 2]. The standard of care for complicated or perforated diverticulitis has evolved from a Hartmann's procedure, to resection 
and primary anastomosis, then to treatment with antibiotics and percutaneous drainage in a carefully selected subset of patients (Hinchey II).

Two randomized trials have demonstrated the safety and efficacy of primary anastomosis in complicated diverticulitis. The first trial by Binda et al was stopped prematurely after inclusion of only 90 out of the targeted 600 patients, because of slow accrual.[26] Being underpowered, the mortality (2.9 vs $10.7 \%$; $P=0.247)$ and morbidity ( 35.3 vs $46.4 \%$; $P=0.38$ ) were not significantly different between the patients undergoing resection with primary anastomosis and those with Hartmann procedure. The second trial of Oberkofler et al reported a comparable overall complication rate when both resection and stoma reversal operations were evaluated $(84 \%$ vs. $80 \%, P=0.813)$, but with more serious complications in the Hartmann's group.[27]

The choice of doing either a Hartmann's procedure or a primary anastomosis in the individual patient needs careful clinical evaluation of the perceived risks and benefits. Recommendations are still largely based on case studies and expert opinion. [28] Results from the resection arm in the LADIES trial will likely provide some answers in the future (Figure 2).[29] The level of training of the operating surgeon also dictates which treatment strategy is used.

\section{Laparoscopic lavage}

The use of laparoscopic lavage for perforated purulent diverticulitis has gradually increased since its introduction in 1996. Prospective and retrospective data have shown that evacuating the pus and lavaging the peritoneal cavity through the 
laparoscope is enough to treat selected patients with perforated diverticulitis. The proponents of this method believe in its simplicity and effectiveness whereas the skeptics argue that too many patients need urgent surgery afterwards. Four trials have been undertaken in recent years and early results from three of these have now been published (Figure 2). The LADIES trial is a four-arm RCT from the Netherlands, investigating the surgical treatment of complicated diverticulitis. [29] The LOLA arm, designed to investigate whether laparoscopic lavage and drainage is a safe and effective treatment for patients with purulent peritonitis, was stopped prematurely after recruitment of 90 patients, due to a significantly increased number of adverse events in the lavage group compared to the sigmoidectomy group in interim analysis. Need for in-hospital surgical re-interventions accounted for most of the adverse events with 18 occurring in the lavage group compared to two in the sigmoidectomy group $(\mathrm{p}=0.0011)$. The authors have concluded that laparoscopic lavage was not superior to sigmoidectomy in terms of major morbidity and mortality at 12 months following surgery and that re-intervention rates are higher in the laparoscopic arm.[29] They also note that in $75 \%$ of those in the laparoscopic arm initial lavage does allow source control but better measures are required to identify those with persistent perforations and perforated cancers.

The results of a second study, the SCANDIV trial, has recently been reported. The authors found an increase in reoperations in those treated with lavage without faecal peritonitis compared to colonic resection $(20.3 \%(15 / 74)$ versus $5.7 \%(4 / 70)$ $\mathrm{p}=0.01$ ). The authors conclude that laparoscopic lavage does not reduce severe short-term post-operative complications and has led to worse outcomes such as higher reoperation rates and therefore could not support the use of lavage for 
perforated diverticulitis.[30] However, the long-term results comparing need for future events (stoma take-backs; new diverticulitis episodes; need for elective procedures) are awaited for overall morbidity and outcome comparison.

Currently, the LapLAND study (NCT01019239) from Ireland, and the DILALA (ISRCTN82208287) are comparing laparoscopic lavage versus resection for Hinchey 3 diverticulitis. The DILALA short-term results in 83 perforated Hinchey III diverticulitis patients randomised between laparoscopic lavage and Hartmann procedure have demonstrated the feasibility of lavage.[31] Long-term outcomes are now needed to evaluate the overall benefit such as avoidance of stoma formation, mortality, and re-operation rates for recurrent symptoms or attacks. Current evidence from RCT's therefore suggests a higher short-term reoperation rate in those treated with laparoscopic lavage and no evidence of a reduction in major complications.

\section{Outcomes and follow-up}

\section{Recurrence}

Reported recurrence rates following an episode of acute diverticulitis requiring hospital admission for medical treatment vary from $13.3 \%$ to $42 \%$, depending on the diagnostic criteria used for acute diverticulitis and the follow period reported. The largest of these retrospective series reported data on 2366 medically treated patients with a median follow up of 8.9 years with a recurrence rate of $13.3 \%$. [32] The majority of recurrences reported in these studies occurred early following the 
initial presentation. The true burden of recurrent disease may be greater as none of these studies reported episodes of recurrence treated in the community. Recent studies have proposed that the majority of patients do not recur and that, if they do, the severity of the disease is not likely to be higher than the previous uncomplicated episodes.[33] In fact, as demonstrated in the DIVER trial, the frequency of perforation nearly halves with each subsequent episode, from $25 \%$ in the first episode to $12 \%$ with the second to $6 \%$ with the third and to $1 \%$ with further episodes.[34] Other factors, such as age, severity of the disease, immunocompromising co-morbidities, family history, or extent of the involved colon have not been clearly proven as risk factors for recurrence.

Recurrent diverticulitis does not seem age dependent. There are conflicting data regarding the risk of recurrence for younger (age $<50$ years) versus older patients. In a systematic review, disease recurrence rates in younger patients were significantly higher than that of elderly patients (RR $1.70,95 \% \mathrm{Cl} 1.31-2.21)$. [35] However, the included studies did not report their follow-up period per group clearly, thus potentially introducing a follow-up bias. More recent data suggest that recurrence rate and outcome is not worse in younger patients. In a recent large retrospective cohort recurrence rate after a median follow-up of 22 months is comparable among groups (25.6\% (111 of 463 ) for younger patients versus $23.8 \%$ (208 of 978) in patients over 50 years of age. [36]

\section{Mortality}

The largest studies reporting the mortality associated with hospital admission for acute diverticulitis have used data from the NIS and reported in hospital mortality 
only. These studies have reported a reduction in mortality following hospital admission over time with a reduction from $1.6 \%$ in 1998 to $1.0 \%$ in $2004-2005$ and a $55 \%$ relative reduction in in-hospital mortality from $4.5 \%$ to $2.5 \%$ from $2002-2007$ with a reduction in mortality following surgery for acute diverticulitis from $5.7 \%$ to 4.3\% across the same period.[37]

Need for colonoscopy at follow up

Current guidelines still recommend routine follow-up colonoscopy after a first attack of acute diverticulitis to confirm the diagnosis and exclude malignancy.[38] The recommendation for colonoscopy after an episode of acute diverticulitis is merely based on expert opinion and dates back to the time before widespread use of $\mathrm{CT}$ to diagnose acute diverticulitis. Colonoscopy is burdensome, costly, timeconsuming, and has the risk of procedure-related morbidity. The yield of colonoscopy after acute diverticulitis diagnosed by adequate imaging techniques is questionable.

There are two different issues posed by those in favour of colonoscopy: (a) the need to exclude malignancy (fear of misdiagnosis), and (b) a presumed higher risk of colorectal carcinoma (CRC) in patients who encountered acute diverticulitis. Patients with diverticulosis or diverticulitis have no higher incidence of polyps or CRC when using age-stratified analysis.[39] The yield of advanced colonic neoplasia during colonoscopy after acute diverticulitis is equivalent to that detected in asymptomatic average-risk screening participants. A systematic review has found an estimated pooled prevalence of $5.0 \%(\mathrm{Cl} ; 3.8-6.7 \%)$ for advanced colonic neoplasia and $1.5 \%(\mathrm{Cl} ; 1.0-2.3 \%)$ for $\mathrm{CRC}$ at follow-up after an episode of CT 
confirmed acute diverticulitis.[40] Follow-up colonoscopy may be needed in patients with an equivocal diagnosis at CT or with a protracted clinical course. Patients presenting with rectal bleeding or with change in bowel habit prior to their initial episode may also warrant a colonoscopy. A recent study has compared colonoscopy and CTC in the follow-up of 108 diverticulitis patients: CTC is better tolerated but the detection accuracy of small polyps is poor, and no advanced neoplasia was found in this cohort.[41]

\section{Elective colectomy after resolved acute diverticulitis}

Routine elective (segmental) colectomy after two attacks of diverticulitis was once considered standard of care, but this has changed with new evidence.[42] The risk of perforation and peritonitis decreases with each attack, contrary to previous beliefs. [43] The outcomes following elective surgery in patients having undergone successful non-operative management indicate patients have more complications and higher costs than in patients following resection for cancer with up to one in five patients having persistent symptoms. [44, 45] Results from the DIRECT trial (NTR1478), a randomised comparison of elective resection for recurrent diverticulitis versus non-operative treatment, are expected following the interruption of the trial after interim analysis. [46] Given the relative confusion that exists about the natural history of uncomplicated diverticulitis, it is recommended that the decision to offer an elective colectomy should be individualized. 


\section{Discussion}

This review presents current available evidence on the diagnosis and the medical and surgical treatment of patients with acute diverticulitis and its complications. Current evidence supports a stratified approach to management based on clinical and radiological features. Due to the broad nature of this review we were unable to follow standard methodologies for systemic review. However we have reported our search strategy and only included articles which were relevant to the current management of acute diverticulitis and its complications.

The diagnosis of acute diverticulitis is made on clinical suspicion however to allow appropriate risk stratification diagnostic imaging is essential. The modality of choice for radiological investigation is $\mathrm{CT}$. It allows stratification of patients into those with uncomplicated simple acute diverticulitis and those with complicated disease. This distinction is imperative if current best evidence is to be applied to this group of patients. Current guidelines suggest that all patients with a clinical suspicion of acute diverticulitis and no prior history should have the diagnosis confirmed by radiological imaging on that admission.[47]

Antibiotic therapy has been mandated in patients with acute diverticulitis however there is now evidence from 2 RCT's and a Cochrane review which suggest that in those patients with CT confirmed uncomplicated acute diverticulitis that antibiotics can be safely withheld.[24, 25] The full results of the DIABOLO trial will be required before firm recommendations on the use of antibiotics in this group of patients can be issued however the currently reported results are encouraging. 
In cases of complicated disease with free perforation and purulent peritonitis the current trend towards the use of laparoscopic lavage has not been supported by two recently published trials. [29, 30] Laparoscopic lavage in the short term was associated with increased morbidity and mortality with higher re-intervention rates when compared to sigmoid resection. Long term results from these studies will be required to determine if any long term advantages to minimally invasive treatments such as stoma avoidance and long term need for surgical intervention are apparent.

In patients undergoing an open procedure there is no strong evidence to support the use of a Hartmann's procedure or primary anastomosis with only 2 small trials completed to date both of which lacked power.[26] The choice between the two procedures often comes down to the level of experience of the operating surgeon along with patient specific risk factors such as comorbidity, sepsis and degree of contamination. Results from the resectional arm of the LADIES trial may help inform current practice in this area.

Following admission with acute diverticulitis recurrence rates are low and current evidence suggests no increase in risk of recurrence in younger patients. Mandated elective resection after 2 episodes of acute diverticulitis is no longer supported given the low risk of recurrence and subsequent development of complicated disease therefore decisions regarding elective resection should be made on an individual patient basis. 
Current understanding of acute diverticulitis permits a diversified management plan, and a stratified approach tailored to the disease severity. Most mild episodes can be treated as an outpatient without need for antibiotics or dietary restrictions (Table 3). The optimal surgical strategy is to be further refined. 


\section{Conflict of interest statement}

MB - Has received grants for diverticulitis research from the Dutch Health Care and Efficacy Research (ZonMW), the Dutch Digestive Diseases Foundation (MLDS), and non-diverticulitis related grants from Baxter, Abbott, Ipsen, LifeCell/Acelity, and GSK. She has spoken at a Dr Falk Pharmaceuticals Symposia as an invited speaker on diverticulitis.

DH - Has received research funding from the Royal College of Surgeons of England, Research into Ageing and the BUPA foundation for research on diverticular disease. He has spoken at a Dr Falk Pharmaceuticals Symposia as an invited speaker on diverticular disease.

GV - none

KS - none

\section{Contributions}

$\mathrm{KS}$ and $\mathrm{MB}$ planned the review. All authors (MB, DH, GV, KS) drafted sections and performed literature searches. All authors contributed to several revisions of the manuscript sections towards the final version and approved the submitted manuscript. 
Figures and Tables

Figure 1. Hinchey classification

Legend: The classical Hinchey classification of (I) mesocolic/pericolic inflammation and/or abscess, (II) a (larger) pelvic abscess, (III) perforation with localized or generalized purulent peritonitis, and (IV) perforation with fecal contamination and generalized peritonitis. Reproduced with permission from BJSS, John Wiley

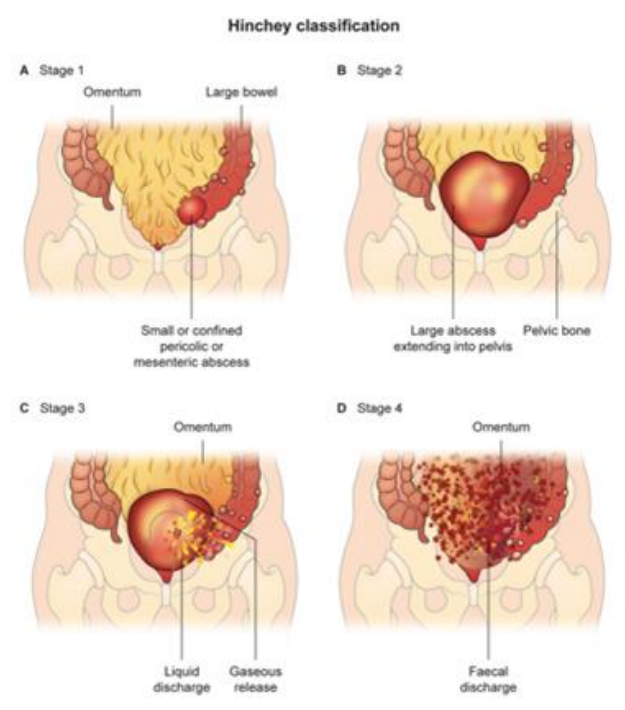

Figure 2. Evolving management strategies for acute complicated diverticulitis Legend: Evolving concept in surgical management with the development of adjunct therapies and development of supportive disciplines. A more tailored, personalized 
treatment is developing. Results from ongoing RCTs will further provide riskbenefit estimates for appropriate decision-making.

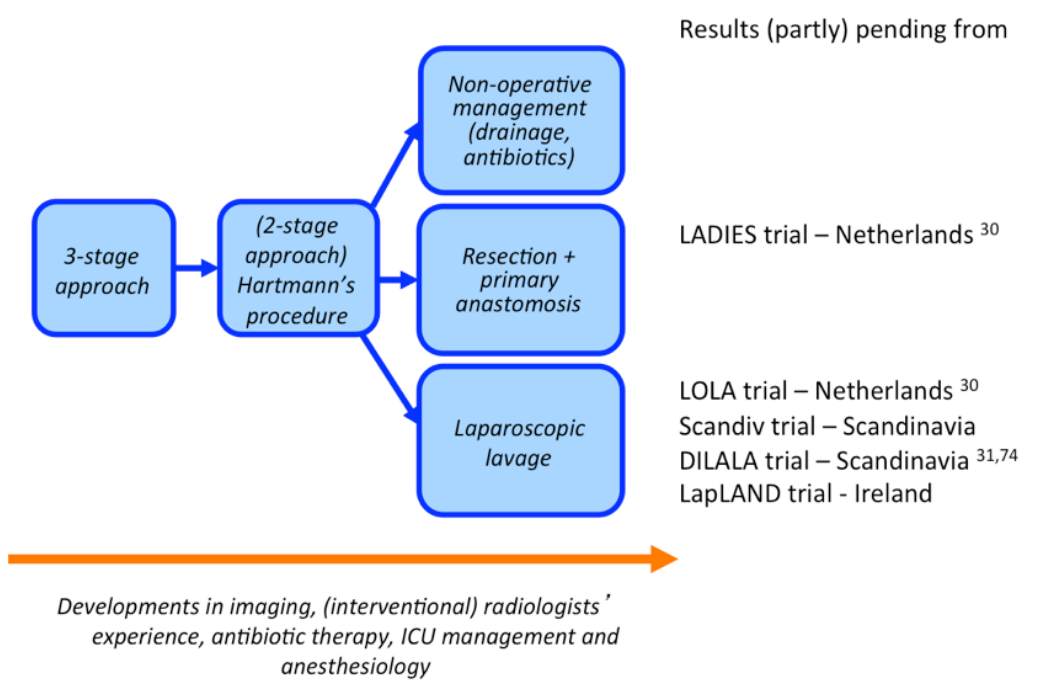


Table 1. Classification systems for acute diverticulitis

Table 1. Classification for acute diverticulitis.

\begin{tabular}{|c|c|c|c|c|}
\hline $\begin{array}{l}\text { Original } \\
\text { Hinchey } \\
\text { classification }{ }^{16}\end{array}$ & $\begin{array}{l}\text { Modified Hinchey } \\
\text { classification } \\
\text { (Wasvary) }^{17}\end{array}$ & $\begin{array}{l}\text { Modified Hinchey } \\
\text { classification with } \\
\text { CT findings }{ }^{18}\end{array}$ & $\begin{array}{l}\text { Ambrosetti CT } \\
\text { classification }{ }^{19}\end{array}$ & $\begin{array}{l}\text { Dharmarajan } \\
\text { Complicated } \\
\text { diverticulitis } 20\end{array}$ \\
\hline & $\begin{array}{l}0 \text { Mild clinical } \\
\text { diverticulitis }\end{array}$ & $\begin{array}{l}0 \text { Diverticulae } \pm \\
\text { colonic } \\
\text { wall thickening }\end{array}$ & \multirow{2}{*}{$\begin{array}{l}\text { Moderate } \\
\text { diverticulitis } \\
\text {-Localized } \\
\text { sigmoid wall } \\
\text { thickening (>5 } \\
\text { mm) } \\
\text {-Pericolic fat } \\
\text { stranding }\end{array}$} & $\begin{array}{l}1 \text { Localised free } \\
\text { air (mesocolic) } \\
\text { without abscess }\end{array}$ \\
\hline \multirow[t]{2}{*}{$\begin{array}{l}\text { I Pericolic } \\
\text { abscess } \\
\text { or phlegmon }\end{array}$} & $\begin{array}{l}\text { la Confined } \\
\text { pericolic } \\
\text { inflammation or } \\
\text { phlegmon }\end{array}$ & $\begin{array}{l}\text { 1a Colonic wall } \\
\text { thickening with } \\
\text { pericolic soft tissue } \\
\text { changes }\end{array}$ & & $\begin{array}{l}2 \text { Collection of } \\
\text { free air }(<2 \mathrm{~cm}) \\
\text { or Abscess }(< \\
4 \mathrm{~cm})\end{array}$ \\
\hline & $\begin{array}{l}\text { 1b Pericolic or } \\
\text { mesocolic abscess }\end{array}$ & $\begin{array}{l}\text { 1b changes + } \\
\text { pericolic } \\
\text { or mesocolic } \\
\text { abscess }\end{array}$ & \multirow{3}{*}{$\begin{array}{l}\text { Severe } \\
\text { diverticulitis } \\
\text {-Abscess } \\
\text {-Extraluminal air } \\
\text {-Extraluminal } \\
\text { contrast }\end{array}$} & $\begin{array}{l}3 \text { Collection of } \\
\text { free air }(>2 \mathrm{~cm}) \\
\text { or Abscess (> } \\
4 \mathrm{~cm})\end{array}$ \\
\hline $\begin{array}{l}\text { II Pelvic, } \\
\text { intraabdominal, } \\
\text { or } \\
\text { retroperitoneal } \\
\text { abscess }\end{array}$ & $\begin{array}{l}\text { II Pelvic, distant } \\
\text { intraabdominal, } \\
\text { or } \\
\text { retroperitoneal } \\
\text { abscess }\end{array}$ & $\begin{array}{l}\text { Il changes + distant } \\
\text { abscess } \\
\text { (generally deep in } \\
\text { the pelvis or } \\
\text { interloop regions) }\end{array}$ & & $\begin{array}{l}4 \text { Free air with } \\
\text { non-localized } \\
\text { free fluid in the } \\
\text { peritoneal cavity }\end{array}$ \\
\hline $\begin{array}{l}\text { III Generalized } \\
\text { purulent } \\
\text { peritonitis }\end{array}$ & $\begin{array}{l}\text { III Generalized } \\
\text { purulent } \\
\text { peritonitis }\end{array}$ & $\begin{array}{l}\text { III Free gas } \\
\text { associated with } \\
\text { localized or } \\
\text { generalized ascites }\end{array}$ & & \\
\hline
\end{tabular}




\begin{tabular}{|l|l|l|l|l|}
\hline & & $\begin{array}{l}\text { and possible } \\
\text { peritoneal wall } \\
\text { thickening }\end{array}$ & & \\
IV Generalized & IV Generalized & Same findings as III & & \\
fecal & fecal & & & \\
peritonitis & peritonitis & & & \\
\hline
\end{tabular}

Table 2. Summary of trial protocol and results for AVOD and DIABOLO studies.

\begin{tabular}{|c|c|c|}
\hline & $\begin{array}{l}\text { AVOD } \\
\mathrm{N}=623\end{array}$ & $\begin{array}{l}\text { DIABOLO } 43 \\
N=570\end{array}$ \\
\hline Population & $\begin{array}{l}M: F=1: 2 \\
\text { Primary }(60 \%) \text { and recurrent } \\
(40 \%) \text { diverticulitis }\end{array}$ & $\begin{array}{l}M: F=1: 1 \\
\text { Primary diverticulitis only }\end{array}$ \\
\hline$R C T Y / N$ & Yes - multicenter, pragmatic & Yes - multicenter, pragmatic \\
\hline Diagnosis & $\begin{array}{l}\text { CT proven diverticulitis: } \\
\text { Ambrosetti mild (no } \\
\text { abscesses) }\end{array}$ & $\begin{array}{l}\text { CT proven diverticulitis: Hinchey } \\
1 \mathrm{a} \text { and } 1 \mathrm{~b} \text { (small abscesses) }\end{array}$ \\
\hline $\begin{array}{l}\text { Interventio } \\
n\end{array}$ & $\begin{array}{l}\text { Broad spectrum antibiotics, } \\
\text { various regimens, } \\
7 \text { days }\end{array}$ & $\begin{array}{l}\text { Amoxicilin/clavulanic acid } \\
4 \times 1200 \mathrm{mg} \text { i.v. for a minimum of } \\
48 \mathrm{hr} \text {, then } 3 \times 625 \mathrm{mg} \text { oral; a total } \\
\text { of } 10 \text { days }\end{array}$ \\
\hline
\end{tabular}




\begin{tabular}{|l|l|l|}
\hline Controls & $\begin{array}{l}\text { No antibiotics } \\
\text { Admission for i.v. fluid }\end{array}$ & $\begin{array}{l}\text { No antibiotics } \\
\text { Observation, no admission } \\
\text { demanded }\end{array}$ \\
\hline Placebo Y/N & No & No \\
\hline $\begin{array}{l}\text { Primary } \\
\text { endpoint }\end{array}$ & $\begin{array}{l}\text { Recovery without } \\
\text { complications at 12 months } \\
\text { follow-up }\end{array}$ & $\begin{array}{l}\text { Time-to-full-recovery at } 6 \\
\text { months follow-up }\end{array}$ \\
\hline
\end{tabular}

Table 3. Summary of evidence for treatment of acute uncomplicated diverticulitis

\begin{tabular}{|l|l|l|l}
\hline Treatment & $\begin{array}{l}\text { Effect on disease } \\
\text { outcome }\end{array}$ & $\begin{array}{l}\text { Grading of } \\
\text { recommendation * }\end{array}$ & Implicatio \\
\hline In-patient vs. out-patient & No difference & B & $\begin{array}{l}\text { Patients wit } \\
\text { and accordir } \\
\text { can be treat }\end{array}$ \\
\hline High fiber & No difference & B & $\begin{array}{l}\text { There is no } \\
\text { prevention c }\end{array}$ \\
\hline Nil by mouth/Bedrest/Laxatives & No published evidence & - & $\begin{array}{l}\text { As evidence } \\
\text { dietary rest } \\
\text { of the treatr }\end{array}$ \\
\hline Antibiotics & No difference & A & $\begin{array}{l}\text { Antibiotics a } \\
\text { treatment o }\end{array}$ \\
\hline Laparoscopic Lavage & No difference & A & $\begin{array}{l}\text { Two random } \\
\text { laparoscopic } \\
\text { associated n } \\
\text { intervention } \\
\text { from these a }\end{array}$ \\
\hline
\end{tabular}

* Grading of recommendations (US Government Agency for Health Care Policy and Research (AHCPR)): 
A: requires at least one RCT as part of the body of evidence.

B: requires availability of well-conducted clinical studies but no RCTs in the body of evidence.

C: requires evidence from expert committee reports or opinions and/or clinical experience of respected authorities. Indicates absence of directly applicable studies of good quality. 
References

1. Viniol, A., C. Keunecke, T. Biroga, et al., Studies of the symptom abdominal pain--a systematic review and meta-analysis. Fam Pract, 2014. 31(5): p. 517-529.

2. Vennix, S., D.G. Morton, D. Hahnloser, et al., Systematic review of evidence and consensus on diverticulitis: an analysis of national and international guidelines. Colorectal Dis, 2014. 16(11):p. 866-78

3. Leifeld, L., C.T. Germer, S. Bohm, et al., [S2 $k$ guidelines diverticular disease/diverticulitis]. Z Gastroenterol, 2014. 52(7): p. 663-710.

4. Pappalardo, G., F.M. Frattaroli, S. Coiro, et al., Effectiveness of clinical guidelines in the management of acute sigmoid diverticulitis Results of a prospective diagnostic and therapeutic clinical trial. Ann Ital Chir, 2013. 84: p. 171-177.

5. Andeweg, C.S., I.M. Mulder, R.J. Felt-Bersma, et al., Guidelines of diagnostics and treatment of acute left-sided colonic diverticulitis. Dig Surg, 2013. 30(4-6): p. 278292.

6. Fujita, T., Feasibility of the practice guidelines for colonic diverticulitis. Surgery, 2012. 151(3): p. 491-492.

7. Andersen, J.C., L. Bundgaard, H. Elbrond, et al., Danish national guidelines for treatment of diverticular disease. Dan Med J, 2012. 59(5): p. C4453.

8. SSAT. SSAT Patient Care Guidelines: Surgical Treatment of Diverticulitis. 2007 [cited 2014 31.12.2014]; Available from: http://www.ssat.com/cgibin/divert.cgi.

9. Jafferji, M.S. and N. Hyman, Surgeon, not disease severity, often determines the operation for acute complicated diverticulitis. J Am Coll Surg, 2014. 218(6): p. 1156-1161. 
10. O'Leary, D.P., N. Lynch, C. Clancy, et al., International, Expert-Based, Consensus Statement Regarding the Management of Acute Diverticulitis. JAMA Surg, 2015. $150(9)$ : p. 899-904.

11. Lameris, W., A. van Randen, H.W. van Es, et al., Imaging strategies for detection of urgent conditions in patients with acute abdominal pain: diagnostic accuracy study. Bmj, 2009. 338: p. b2431.

12. Laurell, H., L.E. Hansson, and U. Gunnarsson, Acute diverticulitis--clinical presentation and differential diagnostics. Colorectal Dis, 2007. 9(6): p. 496-501; discussion 501-492.

13. Kiewiet, J.J., C.S. Andeweg, H. Laurell, et al., External validation of two tools for the clinical diagnosis of acute diverticulitis without imaging. Dig Liver Dis, 2014. 46(2): p. 119-124.

14. van Randen, A., W. Lameris, H.W. van Es, et al., A comparison of the accuracy of ultrasound and computed tomography in common diagnoses causing acute abdominal pain. Eur Radiol, 2011. 21(7): p. 1535-1545.

15. Laméris, W., A. Randen, S. Bipat, et al., Graded compression ultrasonography and computed tomography in acute colonic diverticulitis: Meta-analysis of test accuracy. Eur Radiol, 2008. 18(11): p. 2498-2511.

16. Hinchey, E.J., P.G. Schaal, and G.K. Richards, Treatment of perforated diverticular disease of the colon. Adv Surg, 1978. 12: p. 85-109.

17. Wasvary, H., F. Turfah, O. Kadro, et al., Same hospitalization resection for acute diverticulitis. Am Surg, 1999. 65(7): p. 632-635; discussion 636.

18. Kaiser, A.M., J.K. Jiang, J.P. Lake, et al., The management of complicated diverticulitis and the role of computed tomography. Am J Gastroenterol, 2005. $100(4):$ p. $910-917$. 
19. Ambrosetti, P., M. Grossholz, C. Becker, et al., Computed tomography in acute left colonic diverticulitis. Br J Surg, 1997. 84(4): p. 532-534.

20. Dharmarajan, S., S.R. Hunt, E.H. Birnbaum, et al., The efficacy of nonoperative management of acute complicated diverticulitis. Dis Colon Rectum, 2011. 54(6): p. 663-671.

21. Schechter, S., J. Mulvey, and T.E. Eisenstat, Management of uncomplicated acute diverticulitis: results of a survey. Dis Colon Rectum, 1999. 42(4): p. 470-475; discussion 475-476.

22. Shabanzadeh, D.M. and P. Wille-Jorgensen, Antibiotics for uncomplicated diverticulitis. Cochrane Database Syst Rev, 2012. 11: p. CD009092.

23. de Korte, N., C. Unlu, M.A. Boermeester, et al., Use of antibiotics in uncomplicated diverticulitis. Br J Surg, 2011. 98(6): p. 761-767.

24. Chabok, A., L. Pahlman, F. Hjern, et al., Randomized clinical trial of antibiotics in acute uncomplicated diverticulitis. Br J Surg, 2012. 99(4): p. 532-539.

25. Unlu, C., N. de Korte, L. Daniels, et al., A multicenter randomized clinical trial investigating the cost-effectiveness of treatment strategies with or without antibiotics for uncomplicated acute diverticulitis (DIABOLO trial). BMC Surg, 2010. 10: p. 23.

26. Binda, G.A., J.R. Karas, A. Serventi, et al., Primary anastomosis vs nonrestorative resection for perforated diverticulitis with peritonitis: a prematurely terminated randomized controlled trial. Colorectal Dis, 2012. 14(11): p. 1403-1410.

27. Oberkofler, C.E., A. Rickenbacher, D.A. Raptis, et al., A multicenter randomized clinical trial of primary anastomosis or Hartmann's procedure for perforated left colonic diverticulitis with purulent or fecal peritonitis. Ann Surg, 2012. 256(5): p. 819-826; discussion 826-817. 
28. Moore, F.A., F. Catena, E.E. Moore, et al., Position paper: management of perforated sigmoid diverticulitis. World J Emerg Surg, 2013. 8(1): p. 55.

29. Vennix, S., G.D. Musters, I.M. Mulder, et al., Laparoscopic peritoneal lavage or sigmoidectomy for perforated diverticulitis with purulent peritonitis: a multicentre, parallel-group, randomised, open-label trial. Lancet, 2015. 386(10000): p. 12691277.

30. Schultz, J.K., S. Yaqub, C. Wallon, et al., Laparoscopic Lavage vs Primary Resection for Acute Perforated Diverticulitis: The SCANDIV Randomized Clinical Trial. Jama, 2015. 314(13): p. 1364-1375.

31. Angenete, E., A. Thornell, J. Burcharth, et al., Laparoscopic Lavage Is Feasible and Safe for the Treatment of Perforated Diverticulitis With Purulent Peritonitis: The First Results From the Randomized Controlled Trial DILALA. Ann Surg, 2014.

32. Broderick-Villa, G., R.J. Burchette, J.C. Collins, et al., Hospitalization for acute diverticulitis does not mandate routine elective colectomy. Arch Surg, 2005. 140(6): p. 576-581; discussion 581-573.

33. Etzioni, D.A., V.Y. Chiu, R.R. Cannom, et al., Outpatient Treatment of Acute Diverticulitis: Rates and Predictors of Failure. Diseases of the Colon \& Rectum, 2010. 53(6): p. 861-865 810.1007/DCR.1000b1013e3181cdb1243.

34. Biondo, S., T. Golda, E. Kreisler, et al., Outpatient versus hospitalization management for uncomplicated diverticulitis: a prospective, multicenter randomized clinical trial (DIVER Trial). Ann Surg, 2014. 259(1): p. 38-44.

35. Katz, L.H., D.D. Guy, A. Lahat, et al., Diverticulitis in the young is not more aggressive than in the elderly, but it tends to recur more often: systematic review and meta-analysis. J Gastroenterol Hepatol, 2013. 28(8): p. 1274-1281. 
36. Unlu, C., B.J. van de Wall, M.F. Gerhards, et al., Influence of age on clinical outcome of acute diverticulitis. J Gastrointest Surg, 2013. 17(9): p. 1651-1656.

37. Etzioni, D.A., T.M. Mack, R.W.J. Beart, et al., Diverticulitis in the United States: 19982005: Changing Patterns of Disease and Treatment. Ann Surg, 2009. 249(2): p. 210-217.

38. Feingold, D., S.R. Steele, S. Lee, et al., Practice parameters for the treatment of sigmoid diverticulitis. Dis Colon Rectum, 2014. 57(3): p. 284-294.

39. Meurs-Szojda, M.M., J.S. Terhaar sive Droste, D.J. Kuik, et al., Diverticulosis and diverticulitis form no risk for polyps and colorectal neoplasia in 4,241 colonoscopies. Int J Colorectal Dis, 2008. 23(10): p. 979-984.

40. Daniels, L., C. Unlu, T.R. de Wijkerslooth, et al., Routine colonoscopy after left-sided acute uncomplicated diverticulitis: a systematic review. Gastrointest Endosc, 2014. 79(3): p. 378-389; quiz 498-498.e375.

41. Chabok, A., K. Smedh, S. Nilsson, et al., CT-colonography in the follow-up of acute diverticulitis: patient acceptance and diagnostic accuracy. Scand J Gastroenterol, 2013. 48(8): p. 979-986.

42. McDermott, F.D., D. Collins, A. Heeney, et al., Minimally invasive and surgical management strategies tailored to the severity of acute diverticulitis. Br J Surg, 2014. 101(1): p. e90-99.

43. Buchs, N.C., B. Konrad-Mugnier, A.S. Jannot, et al., Assessment of recurrence and complications following uncomplicated diverticulitis. Br J Surg, 2013. 100(7): p. 976-979; discussion 979.

44. Van Arendonk, K.J., K.M. Tymitz, S.L. Gearhart, et al., Outcomes and costs of elective surgery for diverticular disease: a comparison with other diseases requiring colectomy. JAMA Surg, 2013. 148(4): p. 316-321. 
45. Regenbogen, S.E., K.M. Hardiman, S. Hendren, et al., Surgery for Diverticulitis in the 21st Century: A Systematic Review. JAMA Surg, 2014.

46. van de Wall, B.J., W.A. Draaisma, E.C. Consten, et al., DIRECT trial. Diverticulitis recurrences or continuing symptoms: Operative versus conservative treatment. A multicenter randomised clinical trial. BMC Surg, 2010. 10: p. 25.

47. Fozard, J.B.J., N.C. Armitage, J.B. Schofield, et al., ACPGBI Position Statement on Elective Resection for Diverticulitis. Colorectal Disease, 2011. 13: p. 1-11. 